\title{
ESTRATÉGIAS DE AQUISIÇÃO DE CLIENTES: UM ESTUDO DE MÚLTIPLOS CASOS DE STARTUPS DIGITAIS
}

Matheus Girardi ${ }^{1}$

Aurora Carneiro Zen ${ }^{1}$

${ }^{1}$ Universidade Federal do Rio Grande do Sul 


\title{
ESTRATÉGIAS DE AQUISIÇÃO DE CLIENTES: UM ESTUDO DE MÚLTIPLOS CASOS DE STARTUPS DIGITAIS
}

\begin{abstract}
Resumo: O objetivo deste estudo foi analisar e comparar as estratégias inovadoras utilizadas por startups digitais para adquirir novos clientes. Este estudo revelou que a estratégia mais utilizada por estas startups de produtos digitais para adquirir clientes são técnicas de Growth Hacking em comunidades de nicho. Isto é, publicam versões gratuitas de seus produtos em grupos e retiram as barreiras de entrada como o custo para atrair seus primeiros clientes chamados também de early-adopters. Outras estratégias também são detalhadas e descritas neste estudo. Somente após estabelecer um processo de aquisição de clientes é que a startup pode completar seu ciclo de construir-medir-aprender e ter progresso com aprendizagem validada. Portanto a principal contribuição teórica do presente estudo foi avaliar e comparar os diferentes métodos de aquisição de clientes em startups em estágio inicial, com orçamento muito limitado para investimento em mídias tradicionais.
\end{abstract}

Palavras-chave: startups. marketing digital. growth hacking. aquisição de clientes.

\section{INTRODUÇÃO}

Recentemente, o mundo vem passando por transformações profundas nas mais diversas áreas. $\mathrm{Na}$ última década o paradigma da economia digital permitiu a entrada de novos players que transformaram rapidamente setores consagrados que pareciam ter barreiras de entrada elevadas. Essas empresas possuem como principais características o uso de informações e rede como ativos essenciais. Graças à intangibilidade da informação, as principais funções de negócios podem ser transferidas para fora da organização - para os usuários, fãs, parceiros e ao público em geral. Dado esse contexto, existe uma grande quantidade de startups na busca de soluções que resolvam problemas reais e que tenha alta escalabilidade fazendo uso da informação como principal ativo, o que habilita seu crescimento sem necessariamente incrementar custos na sua estrutura.

Outro fator em comum destas empresas é que todas surgiram como startups antes de consolidar seu modelo de negócios. Ries (2012, p.17), define startup como: “... uma instituição humana desenhada para criar um novo produto ou serviço em condições de extrema incerteza". Blank (2012, p. 22), traz outro conceito que reforça o conceito de que startups existem apenas enquanto buscam um modelo de negócios escalável: "Startups são organizações temporárias criadas para buscar um modelo de negócio escalável e repetível".

Estas organizações geralmente não possuem receita gerada por seus produtos ou serviços, portanto dependem de investimentos externos ao negócio para existir, pois ainda estão na etapa de validação e aprendizagem de seu modelo de negócios. Neste contexto, é fundamental que a startup mantenha um ritmo de construção e aprendizado contínuo. Diante disto,

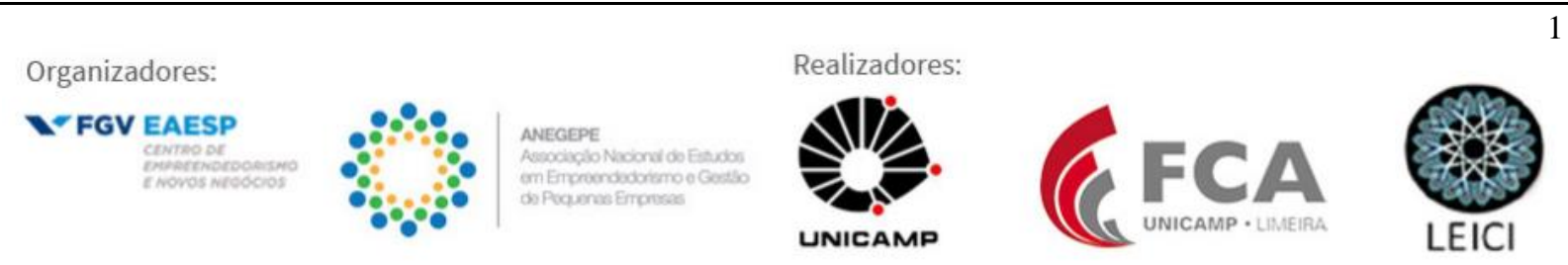


empreendedores de startups tem o desafio de encontrar usuários que experimentem e entreguem feedbacks a respeito de seus produtos e serviços, enquanto ainda não estão consolidadas no mercado, pois caso contrário a startup não consegue aprender e validar suas hipóteses de negócio. Logo, este cenário de escassez e ao mesmo tempo de expansão e validação é o que motiva os empreendedores de startups a buscar estratégias inovadoras e de baixo custo para adquirir clientes que possam validar seus produtos e serviços.

A problemática que se coloca nesse contexto é entender como que startups ainda em estágio pré-operacional e sem receita oriunda de seus produtos e serviços planejam sua ida ao mercado e quais as abordagens de marketing utilizadas para atração de novos usuários sem grandes investimentos. Portanto, essa pesquisa tem como questão central: quais são as estratégias de aquisição de clientes em startups digitais? Com base nessa questão, o objetivo deste artigo é analisar e comparar as estratégias inovadoras utilizadas por startups digitais para adquirir novos clientes. Assim, esse trabalho visa contribuir com o entendimento de quais abordagens utilizadas por startups para adquirir clientes dispostos a validar e promover seus produtos sem grandes investimentos e métodos tradicionais.

\section{STARTUPS DIGITAIS E A AQUISIÇÃO DE CLIENTES}

Blank (2013) define uma startup como "uma organização temporária desenhada para buscar um modelo de negócio repetível e escalável". Os três pontos principais destas organizações são: 1) o modelo de negócio definido por um canvas (business model canvas) de como a empresa buscará a criação de valor para seus clientes; 2) o desenvolvimento de clientes (ao contrário de desenvolvimento de produtos), MVPs (produtos mínimos viáveis) e feedback dos clientes para retroalimentar e priorizar o ciclo de desenvolvimento de funcionalidades; e 3) desenvolvimento ágil incremental e iterativo. Segundo Ries (2012), em seu cerne a startup é uma catalisadora que transforma ideias em produtos. À medida que os clientes interagem com os produtos, geram feedback e dados. Como startups desenvolvem produtos com uma abordagem experimental; a aprendizagem sobre como desenvolver uma empresa sustentável é o resultado desses experimentos.

Esse ciclo de feedback construir-medir-aprender está no centro do modelo da startup enxuta. Dado o cenário de extrema incerteza, acelerar este processo é fundamental para que a startup valide e aprenda sua estratégia de desenvolvimento de produtos ou serviços.

De acordo com Dullius (2016 apud CASSON, 2005; KIRZNER, 1997; VENKATARAMAN,1997), as startups podem ser consideradas novos negócios criados a partir da percepção de uma oportunidade a ser explorada, decorrente da assimetria de informações oriunda de conhecimento diferenciados. Startups tendem a se desenvolver em áreas onde a alta tecnologia é fundamental, associando assim sua criação à utilização deste tipo de tecnologia. Pela exploração de oportunidades para resolver problemas identificados com potencial inovador, elas visam entrar em áreas previamente não exploradas, onde há um potencial de lucro e inovador.

Blank (2015) explica quais são as fases de desenvolvimento de uma startup por meio de uma metodologia que ele chama de "desenvolvimento de cliente". Vale ressaltar que ela não é suficiente como guia para empreendedores, vista que dentro de cada etapa existem diversas atividades que ocorrem afim de percorrer o processo, entretanto ela corrobora para a visão de Ries (2012) do ciclo "construir-medir-aprender" onde é possível notar que o modelo de
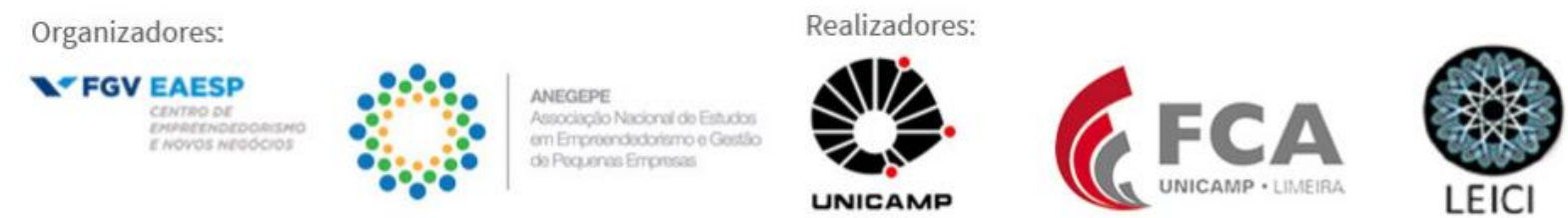
negócio das startups está totalmente suscetível a mudanças dado o aprendizado inerente aos feedbacks dos clientes. O modelo prevê quatro etapas do desenvolvimento de uma startup: descoberta do cliente, validação da solução pelo cliente, geração de demanda e estruturação da empresa. Assim, cada passo é representado por uma trilha circular recursiva, ressaltando que é um processo de retroalimentação, em que hipóteses são geradas, testadas e só será dado o próximo passo se realmente houver validação e aprendizagem dessas hipóteses. Portanto, fica claro que a partir do momento em que a empresa encontra um modelo de negócios repetível e escalável, a startup executa este modelo e deixa de ser uma startup, estabelecendo uma firma e modelo claro de atuação.

Logo é possível definir as startups da seguinte forma: Uma organização temporária em busca de um modelo de negócios repetível e escalável, que tem como base de suas atividades o desenvolvimento de produtos e clientes a partir do processo iterativo de construir-mediraprender. Possui como principal métrica de progresso as descobertas e aprendizados a partir da validação de hipóteses dos empreendedores. Portanto, para fins desta pesquisa, o foco é analisar startups que estão neste momento de incerteza e descoberta contínua para decidir se irão ou não se consolidar como empresas.

\subsection{ENGAJAMENTO E AQUISIÇÃO DE CLIENTES EM NEGÓCIOS DIGITAIS}

Para abordar o tema de aquisição de clientes em negócios digitais, se faz necessário elucidar qual o conceito de aquisição de clientes de modo tradicional no marketing. Segundo Buttle (2009), a aquisição de clientes é sempre a tarefa mais importante do marketing no lançamento de qualquer novo produto ou startup. Basicamente os novos clientes podem ser: 1) Novo para um segmento de produto, ou 2) novo para a empresa como um todo (BUTTLE, 2009). Os métodos mais utilizados para prospecção e aquisição de clientes no marketing tradicional para o mercado B2C, segundo Buttle (2009), estão descritos resumidamente Tabela 1:

\section{Tabela 1 - Métodos de Aquisição de Clientes}

\begin{tabular}{|c|c|c|}
\hline Método & Descrição & Objetivos \\
\hline Propaganda & $\begin{array}{l}\text { É a criação e entrega de mensagens } \\
\text { e mídias para audiências } \\
\text { direcionadas por meio de compra } \\
\text { de espaço ou tempo em veículos de } \\
\text { comunicação não-próprios. }\end{array}$ & $\begin{array}{l}\text { Geralmente possuemdois objetivos: } \\
\text { a) Cognição: Fazer com que a audiência conheça } \\
\text { o produto } \\
\text { b) Sentimento: Provocar sentimentos em relação a } \\
\text { marca }\end{array}$ \\
\hline Promoções de Venda & $\begin{array}{l}\text { Qualquer incentivo temporário } \\
\text { disparado para potenciais } \\
\text { consumidores, clientes, canais de } \\
\text { venda e vendedores. }\end{array}$ & $\begin{array}{l}\text { Oferecer uma oportunidade temporária e imediata } \\
\text { de comprar um produto. } \\
\text { Exemplos: Amostras grátis; Experimentação } \\
\text { grátis; Descontos temporários; Cupons; Cash- } \\
\text { back; Bônus; Pacotes; Experimentação premium } \\
\text { grátis; Promoções cross; Loterias; Competições. }\end{array}$ \\
\hline $\begin{array}{l}\text { Buzzmarketing ou } \\
\text { WOW (Word-of- } \\
\text { mouth) }\end{array}$ & $\begin{array}{l}\text { É o famoso boca-boca, } \\
\text { comunicação interpes soal sobre um } \\
\text { produto ou organização em que o } \\
\text { receptor assume que o comunicador } \\
\text { não está vinculado a nenhuma ação } \\
\text { comercial. }\end{array}$ & $\begin{array}{l}\text { Vincular suas marcas e produtos a assuntos do } \\
\text { dia-dia das comunidades em que estão se } \\
\text { inserindo. Este tipo de abordagem por parecer } \\
\text { desvinculado de propósito comercial, soa aos } \\
\text { consumidores algo independente e confiável. }\end{array}$ \\
\hline Merchandising & $\begin{array}{l}\text { Qualquer estímulo que influencia o } \\
\text { comportamento de compra no }\end{array}$ & $\begin{array}{l}\text { Utilizado para influenciar o comportamento dos } \\
\text { consumidores em uma loja ou ponto de venda. }\end{array}$ \\
\hline
\end{tabular}

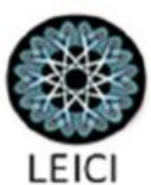




\begin{tabular}{|c|c|c|}
\hline & $\begin{array}{l}\text { varejo ou em qualquer ponto de } \\
\text { venda. }\end{array}$ & $\begin{array}{l}\text { Exemplos comuns: } \\
\text { 1) Posicionamento nas gondolas e seções do } \\
\text { varejo } \\
\text { 2) Displays especiais } \\
\text { 3) Displays de janelas } \\
\text { 4) Impressões de ponto de venda }\end{array}$ \\
\hline Indicações (MGM) & $\begin{array}{l}\text { Estratégia de aquisição de novos } \\
\text { clientes por indicações feitas pela } \\
\text { base atual de clientes. }\end{array}$ & $\begin{array}{l}\text { Sugerir que clientes já existentes convidem seus } \\
\text { amigos e ganhem benefícios por esta ação. O } \\
\text { objetivo é criar uma base de prospecção } \\
\text { qualificada e reduzir o custo de aquisição de } \\
\text { clientes. } \\
\text { Exemplos: } \\
\text { 1) Cupons de descontos para quem convida e é } \\
\text { convidado } \\
\text { 2) Eventos para consumidores com convites } \\
\text { extras para seus convidados } \\
\text { 3) Concursos com premiações para indicações }\end{array}$ \\
\hline Publicidade Gratuita & $\begin{array}{l}\text { Ações de publicidade geralmente } \\
\text { são caracterizadas por ações de } \\
\text { marketing de baixo custo em } \\
\text { relação ao alto impacto social e de } \\
\text { mídia gerados. }\end{array}$ & $\begin{array}{l}\text { Reduzir os custos de propaganda. } \\
\text { Um exemplo foi quando a Virgin Cola foi lançada } \\
\text { nos Estados Unidos, a empresa contratou um } \\
\text { tanque de guerra para desfilar na Times Square e } \\
\text { "atirar" no luminoso da Coca Cola. Muitas } \\
\text { emissoras de TV foram cobrir o evento e deste } \\
\text { modo a Virgin ganhou muita publicidade gratuita } \\
\text { sobre o seu lançamento. }\end{array}$ \\
\hline $\begin{array}{l}\text { Marketing Direto: } \\
\text { Telemarketing }\end{array}$ & $\begin{array}{l}\text { Contato direto com os clientes ou } \\
\text { potenciais clientes por telefone afim } \\
\text { de ofertar um produto ou serviço. }\end{array}$ & $\begin{array}{l}\text { Reduzir o custo com vendas em campo. Também } \\
\text { é muito utilizado para qualificação de leads, } \\
\text { retenção de clientes e resposta de reclamações. }\end{array}$ \\
\hline $\begin{array}{l}\text { Marketing Direto: } \\
\text { SMS }\end{array}$ & $\begin{array}{l}\text { Contato direto com clientes ou } \\
\text { potenciais clientes por mensagens } \\
\text { de texto afim de ofertar um } \\
\text { produto, serviço ou promoção. }\end{array}$ & $\begin{array}{l}\text { Tem sido eficaz no envio de promoções e } \\
\text { descontos de última hora embares e restaurantes. } \\
\text { Dado que não é necessário resposta dos } \\
\text { consumidores, tem um bom nível de ativação. }\end{array}$ \\
\hline $\begin{array}{l}\text { Marketing Direto: } \\
\text { E-mail }\end{array}$ & $\begin{array}{l}\text { Contato direto com consumidores } \\
\text { em potencial para oferta de } \\
\text { produtos ou serviços. }\end{array}$ & $\begin{array}{l}\text { Promoção de produtos ou serviços para uma } \\
\text { audiência qualificada. }\end{array}$ \\
\hline Pitchs & $\begin{array}{l}\text { São apresentações realizadas em } \\
\text { público ou virtuais para apresentar } \\
\text { um produto ou serviço afim de } \\
\text { convocaro público a comprar. }\end{array}$ & $\begin{array}{l}\text { Promover o produto ou serviço para uma } \\
\text { audiência restrita como se fossem advogados do } \\
\text { produto e medir a conversão neste sentido. Serve } \\
\text { também para avaliar se os elementos de venda } \\
\text { estão adequados para campanhas futuras de } \\
\text { buzzmakerting }\end{array}$ \\
\hline $\begin{array}{l}\text { Incluir produtos em } \\
\text { Produções Artísticas }\end{array}$ & $\begin{array}{l}\text { Consiste na prática de incluir } \\
\text { produtos ou serviços em cenas de } \\
\text { produções artísticas como filmes, } \\
\text { séries, reportagens ou teatro. }\end{array}$ & $\begin{array}{l}\text { Incluir os produtos e serviços nos dia-dia do } \\
\text { consumidores e criar identificação e sentimentos a } \\
\text { partir do uso destes produtos e serviços por } \\
\text { pessoas famosas. }\end{array}$ \\
\hline
\end{tabular}

Todos os métodos possuem como métrica base o volume de clientes convertidos por cada ação. Este é o requisito básico para quantificar e validar a performance de cada uma das estratégias de aquisição. As três principais métricas (KPIs) para as atividades de aquisição de clientes são (BUTTLE, 2009): 1. Quantos clientes foram convertidos? 2. Qual o custo para cada cliente convertido? 3. Qual o valor para cada cliente convertido? 
No contexto da economia digital, é fundamental que as empresas além de conduzir os consumidores a ação de compra, transformem estes clientes em defensores da marca. Tal ação permite que a empresa explore efeitos de rede na comunidade que favorecem sua aquisição de clientes de modo indireto. Na prática, essa é a diferença fundamental entre o marketing digital e o marketing tradicional (KOTLER, 2017). Portanto, o marketing digital não pretende substituir o marketing tradicional. Pelo contrário, ambos devem coexistir, com papéis permutáveis, ao longo do relacionamento com os consumidores (MARION; FIXSON, 2016). $\mathrm{Na}$ economia digital, o caminho do consumidor deve ser redefinido como os cinco As assimilação, atração, arguição, ação e apologia -, que refletem a conectividade entre os consumidores. Essa mudança consiste basicamente na capacidade dos clientes se conectarem em rede ou comunidades digitais na economia atual.

Enquanto no modelo tradicional, todas as comunicações com relação a empresa de maneira pública, eram geradas da empresa para os seus clientes (1-n). No marketing digital é possível que novos agentes públicos sejam criados, potencializando assim novos canais e formas de adquirir clientes, propiciando um modelo de comunicação (n-n) (HUGHES, 2005; MERCHANT, 2012).

Esta nova dinâmica de aquisição e comunicação, sugere então que empreendedores e profissionais do marketing extrapolem os métodos tradicionais de aquisição, a fim de fazer com que suas empresas participem destas conversas e comunidades digitais (KOTLER, 2017). Na próxima sessão serão abordados quais são esses novos métodos.

\subsection{ESTRATÉGIAS DE AQUISIÇÃO DE CLIENTES EMSTARTUPS DE PRODUTOS DIGITAIS}

Como já abordado na introdução, startups são empresas temporárias em procura de um modelo escalável. Essa escalabilidade, segundo Ismail (2015), significa que devem perseguir um modelo de negócio que pode crescer de maneira exponencial, sem necessariamente crescer sua operação na mesma proporção.

No modelo proposto por Ismail (2015), engajamento é um atributo fundamental para o dimensionamento da organização em relação à Comunidade e Multidão e para a criação de efeitos de rede externos. Isso pois não importa o quanto seu produto ou serviço seja promissor, a menos que sua startup seja capaz de otimizar o engajamento de sua Comunidade e Multidão, ele irá definhar e desparecer.

A importância do engajamento é justificada pelo argumento de que "ao mesmo tempo em que está cada vez mais difícil de ser conquistado, o indivíduo, uma vez engajado, traz benefícios crescentes para as marcas" (CERQUEIRA, SILVA, 2011). Pois torna um cliente mais que um comprador, torna-o um embaixador da marca, expandindo a relação cliente - empresa para o âmbito coletivo e social potencializado por meio das redes sociais (MERCHANT, 2012).

O mercado atualmente conta com mais de 2 milhões de aplicativos disponíveis, fazer com que sejam descobertos e promovidos é um dos principais desafios das startups. Porém com poucos recursos não é possível fazer uso de canais e mídias pagas, portanto a chave para expansão das startups é buscar o engajamento em escala de formas não tradicionais, afim de não competir nos mesmos canais de grandes empresas e mesmo assim ser percebido (RASMUSSEN; TANEV, 2016).

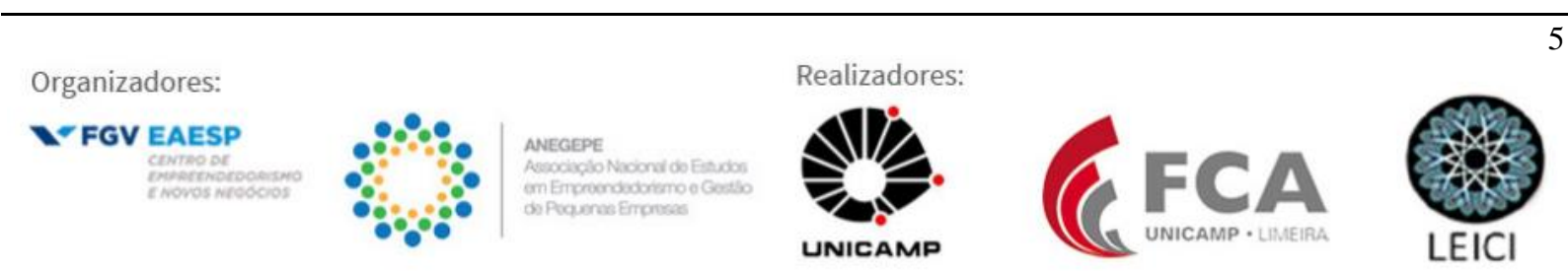


Neste contexto surgem alguns métodos de aquisição de clientes peculiares ao ambiente digital e fortemente utilizados por startups como os que serão descritos na sequência, que possuem em sua essência a facilidade de medição e baixo custo de implementação. $O$ que na perspectiva das startups é fundamental pois é aderente ao processo: Medir - Construir Aprender, proposto pelo Lean Startup.

\subsubsection{Nova abordagem de crescimento: Growth Hacking}

Holiday (2013) descreve no início do seu livro como era a rotina dos executivos de marketing durante os últimos 75 anos como: Contratar anúncios, planos de eventos, relatórios, designers criativos, aprovar campanhas e falar sobre: Marca, Custo de Aquisição, Aproximação, Mídia Espontânea, Valor Agregado e etc. Até o dia em que se deparou com o seguinte anúncio:

"Growth Hacker serão os novos executivos de marketing". O autor descreve Growth Hackers como um hibrido entre profissionais de marketing e engenheiros de software, capazes de responder à pergunta de como conseguir mais clientes. Com respostas não tradicionais, tais como: fazendo testes $\mathrm{A} / \mathrm{B}$, utilizando landing pages, considerando fatores virais, capacidade de entrega de e-mail para não-clientes.

De acordo com Holiday (2013) o objetivo final de um growth hacker é construir uma máquina de marketing que atinge milhões de pessoas sozinha. $\mathrm{O}$ autor também descreve que na era digital o Growth Hacker só faz uso de técnicas que possam ser testadas, mensuradas em escala e com baixo custo. As ferramentas utilizadas são: redes sociais, e-mails marketing, anúncios pagos por clique, blogs, influenciadores, games e plataformas, deixando de lado comerciais, publicidade e qualquer ação que envolva muitos recursos financeiros. Esta lógica de baixo custo e alta exploração e transpiração em busca de estratégias de engajamento de multidões que tornam o tema tão atraente para startups de produtos digitais.

\subsubsection{Buzzmarketing}

Hughes (2005, p.10) define: "Buzzmarketing capta a atenção dos consumidores e da mídia até o ponto em que falar sobre sua marca ou empresa se torna divertido, fascinante e notável." Este método basicamente busca iniciar conversas em todos os tipos de comunidades que seu produto ou serviço possa participar a fim de gerar engajamento e interesse pela sua empresa. Para isso ser possível, é importante que a empresa afim de investir nesta estratégia, conte boas histórias, histórias tão boas que mereçam ser compartilhadas na comunidade em que está inserida. Hughes (2005), comenta que estas histórias para serem compartilhadas por outras pessoas, devem versar sobre um dos seis temas: (i) Um tabu; (ii) Algo muito incomum; (iii) Uma ideia ultrajante; (iv) Algo extremamente engraçado e hilário; (v) Algo muito marcante; e (vi) Algo secreto. Outra forma de gerar buzz na comunidade digital, segundo o autor é por meio da criação de ferramentas e e-books gratuitos. Esta técnica usa das técnicas do marketing de conteúdo para gerar buzz sobre os assuntos no qual a startup tem interesse em explorar (HUGHES, 2005).

Buzzmarketing portanto é toda ou qualquer forma de estimular a comunidade a escrever ou falar sobre um determinado produto ou serviço. Nos meios digitais isso ocorre por meio de avaliações, textos em blogs, comentários e publicações espontâneas em redes sociais. Todas estas ações influenciam no valor da startup e é determinante no aumento do tráfego nos seus canais de aquisição de clientes (LUO; ZHANG, 2013).

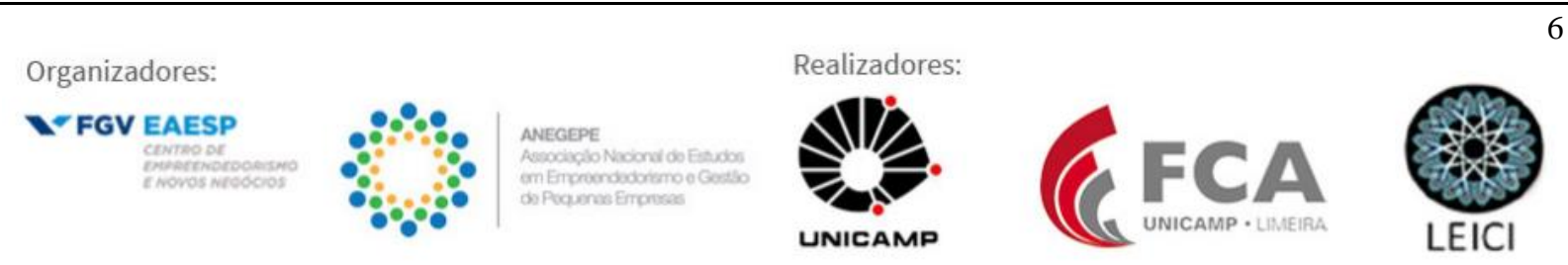




\subsubsection{Gamification}

Kotler (2017) define que gamificação é uma abordagem para estimular engajamento e agradabilidade no uso de um produto digital, pois faz uso de mecanismos de jogos para aumentar a interação com uma marca ou serviço. Como jogos são divertidos, viciantes e competitivos, estimulam subconscientemente determinados comportamentos nos clientes e potenciais clientes.

A forma mais antiga de gamificação para programas de fidelidade pode ser vista nos programas de milhagem de companhias aéreas, que encorajam os clientes a escolher a mesma empresa para todas as necessidades de viagem. Os clientes podem se inscrever em um programa de milhagem para acumular pontos ou milhas, que podem ser trocados por passagens aéreas ou outros produtos e serviços. Para motivar os clientes a acumular pontos, a maioria dos programas possui níveis. Os níveis mais altos, com frequência chamados de níveis de elite, estão associados a um status superior, com direito a mais privilégios.

Existem diversas razões pelas quais a gamificação é considerada a melhor ferramenta para o engajamento. Em primeiro lugar, esse sistema explora o desejo humano de alcançar metas mais altas e ser reconhecido por suas realizações. Alguns consumidores são motivados por recompensas e outros, pela autorrealização. À semelhança dos jogos, existe certo nível de vício envolvido em perseguir níveis mais altos. Assim, os clientes têm interações contínuas com as empresas, criando uma afinidade mais forte (KOTLER, 2017). No que tange aumentos nas interações, o uso de gamificação em produtos digitais aumenta o tempo de uso dos aplicativos, o volume de contribuições nas comunidades e o número de visitas ao aplicativo em comparação com ambientes não gamificados (LOOYESTYN; KERNOT; BOSHOF; RYAN; EDNEY; MAHER, 2017).

\section{MÉTODO}

A presente pesquisa teve caráter exploratório e qualitativo. Optou-se pela realização de estudos de múltiplos casos com três startups. Os estudos de caso são uma ferramenta adequada para análise de fenômenos contemporâneos, sem a necessidade de controle comportamental sobre os elementos pesquisados Yin (2013). Sendo assim, foram conduzidas entrevistas semiestruturadas com sócios de startups e posterior análise de dados provenientes das entrevistas à luz da revisão de literatura para complementar o estudo de caso. Entrevistas semiestruturadas são entrevistas em profundidade com um grau maior de flexibilidade do que entrevistas estruturadas, porém asseguram que o entrevistador mantenha a entrevista limitada ao escopo de interesse da pesquisa Sreejesh, Mohapatra e Anusree (2014). Este método permite, portanto, que seja possível explorar detalhes de técnicas de aquisição de clientes utilizadas pelos sócios que eventualmente não estavam no roteiro da entrevista.

O critério para seleção das startups levou em conta questões como investimento arrecadado, tempo de dedicação diária dos sócios fundadores, faturamento, tempo de operação, participação em incubadoras e também o tamanho da sua presença em redes sociais. Foi utilizada uma amostra escolhida por conveniência, visto que o pesquisador também possui uma startup e participou de um programa de aceleração, portanto possui conexões com diversos empreendedores. Os entrevistados eram os fundadores de startups que compõe o ecossistema gaúcho de empreendedorismo conforme descreve a Tabela 2:

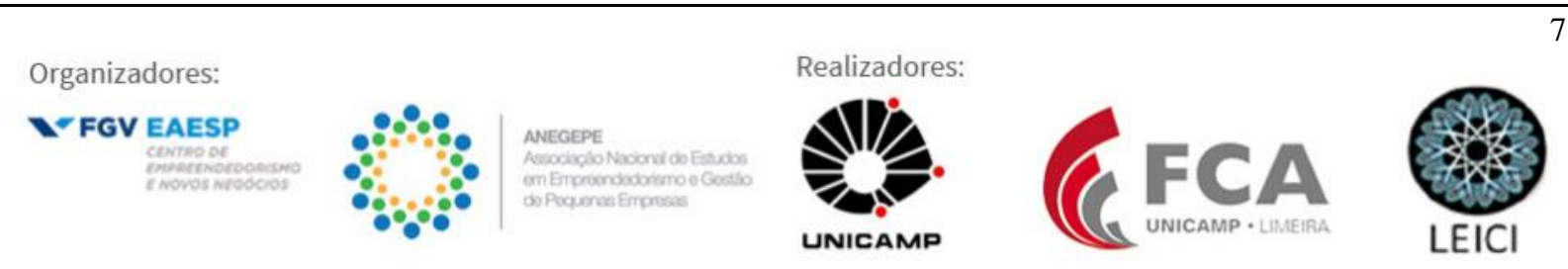


Tabela 2 - Perfil dos Entre vistados

\begin{tabular}{|c|c|c|c|}
\hline Nome & Startup & Cargo & Localidade \\
\hline Gabriel Dngel & Rocket Chat & Founder - CEO & Porto Alegre/RS \\
\hline Lucas Cunha & Santo Contrato & Founder - CMO & Porto Alegre/RS \\
\hline Jonathan Tebaldi & Criativando & Founder - CEO & Nova Bassano/RS \\
\hline
\end{tabular}

Fonte: Elaborado pelo autor

As técnicas de coleta de dados utilizadas nessa pesquisa foram entrevistas semiestruturadas presenciais conduzidas pelo pesquisador e revisão da literatura. Estas técnicas foram escolhidas devido à necessidade de complementação que uma tem em relação à outra. As entrevistas ocorreram na cidade de Porto Alegre/RS, quando viável, dado eventuais limitações de localização e deslocamento serão realizadas por vídeo conferência.

Foi elaborado um roteiro de questões abertas para a entrevista com os representantes das startups, organizado em cinco etapas. A primeira etapa serve para identificação da startup e sua trajetória. $\mathrm{Na}$ segunda parte iremos explorar o modelo de negócio e quais as características do produto digital que a startup está trabalhando. A terceira etapa aborda aspectos sobre os mecanismos de aquisição que a startup utilizou e quais foram os principais motivadores do empreendimento. Na quarta etapa é para abordar quais os resultados obtidos para cada uma das estratégias adotadas. Já na última etapa foi solicitado aos empreendedores que recomendem quais foram as três melhores práticas utilizadas para sua startup.

As técnicas de análise de dados utilizadas nesta pesquisa foram as análises qualitativas dos dados resultantes das entrevistas realizadas, visando identificar quais as principais estratégias de aquisição de clientes utilizadas pelas startups de produtos digitais.

\section{RESULTADOS}

\subsection{CARACTERÍSTICAS DAS STARTUPS}

\subsubsection{ROCKET.CHAT}

A Rocket.Chat é uma startup gaúcha do segmento de Comunicação/Chats que oferece plataforma completa de comunicação open source que surgiu com o intuito de melhorar a comunicação empresarial. Com o uso dessa plataforma, o usuário evita a perda de tempo com caixas de e-mail lotadas, a perda de informações e a necessidade de utilizar diferentes plataformas para se comunicar com quem realmente interessa: colegas, fornecedores, clientes, leads e investidores.

Tendo em vista que o mercado oferecia soluções de chat privadas de código fechado, dificultando o poder de influenciar futuro do produto ou até customizar para os clientes, surgiu o desafio de se criar a melhor plataforma de chat do mundo com código aberto.

A partir desse desafio, em 2015 surgiu a Rocket.Chat: uma plataforma de chat totalmente customizável e colaborativa para organizações. Em dois anos de projeto, a Rocket.Chat reuniu a maior e mais ativa comunidade de chats open source do mundo, com mais de 600 desenvolvedores que voluntariamente se dispuseram a trabalhar para melhorá-la e outros 15 mil que seguem o desenvolvimento para ajudar ativamente testando as novas funcionalidades e discutindo novas ideias.
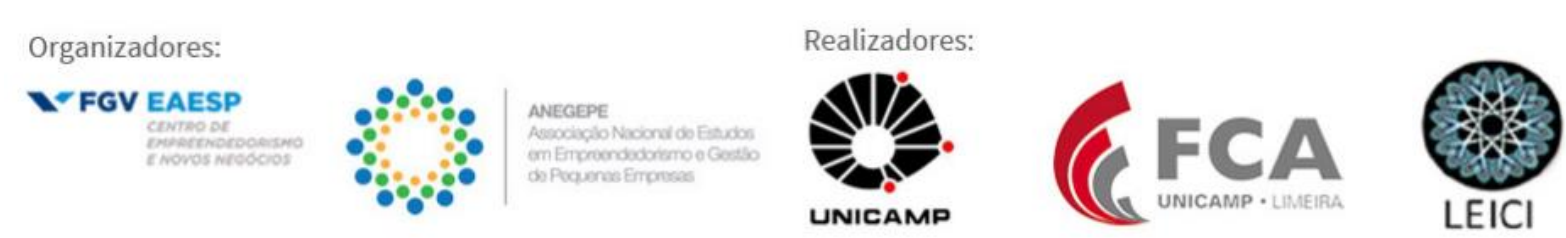
Essa comunidade permite que muito rapidamente se tenha novidades na ferramenta. Hoje ela possibilita a criação de salas (individuais e de grupo, privadas ou públicas, de interação ou só de leitura) com usuários e convidados ilimitados, a conexão do Livechat com o site da organização para captura de leads, vídeo e áudio conferência e compartilhamento de arquivos para permitir a colaboração em projetos, tradução simultânea, histórico de conversas, diferentes tipos de autenticação e segurança de informações. Como o código é aberto, o limite da plataforma fica na imaginação de cada cliente, sendo totalmente customizável e integrável com outros sistemas, como bots de autoatendimento, canais de comunicação de redes sociais ou CRM's.

Atualmente a startup oferece seu produto ao mercado de duas maneiras:

1. Gratuito: onde o usuário instala o Rocket.Chat em sua infraestrutura.

2. Modelo SaaS (Software as a Service), onde a startup oferece uma instalação na nuvem para utilização do Rocket.Chat e cobra uma mensalidade de acordo com o número de usuários do cliente.

Em 2016, a Rocket.Chat recebeu um investimento de 5 milhões de dólares de um dos maiores investidores norte-americanos Harry Weller, via fundo de investimentos NEA (New Enterprise Associates). Este investimento permitiu que a Rocket.Chat investisse em Marketing, Design, construção de aplicativos nativos e continuasse evoluindo sua plataforma para se posicionar como um marketplace de bots e serviços, customizável e distribuído gratuitamente.

\subsubsection{SANTO CONTRATO}

A Santo Contrato é uma startup do segmento de Lawtechs fundada em 2016 na cidade de Porto Alegre que surgiu da necessidade identificada pôr seus atuais fundadores o CEO, Marcel Boff e o COO, Lucas Cunha de aumentar a produtividade e desburocratizar a gestão de contratos e documentos legais entre empresas, advogados e pessoas físicas.

$\mathrm{Na}$ opinião do entrevistado, a elaboração (negociação e validação), gestão de contratos e assinatura é muito caro quando feita na forma tradicional, o que por muitas vezes inviabiliza a formalização de algumas relações, ou então, a procura por opção mais baratas, incorre na elaboração de maus contratos, acarretando em diversos riscos, como por exemplo: a falência de uma empresa.

Diante deste cenário, surge a Santo Contrato, uma plataforma web SaaS que oferece um ambiente online para elaboração, negociação, gestão, e assinatura digital de contratos. A plataforma conecta empresas, advogados e pessoas comuns, para colaborativamente construírem documentos e contratos o mais próximo do perfeito, oferecendo também, templates de contratos que podem servir de base para o início dos contratos.

Os próprios sócios se denominam como uma espécie de Google Docs dos contratos, pois permitem o controle e edição colaborativa dos contratos gerados na plataforma, por meio de sistema inteligente de controle das versões das minutas e seu histórico, além de contar com assinatura digital entre as partes com validade jurídica, de acordo com a Medida Provisória $\mathrm{n}^{\circ}$ 2.200-2/2001.

Atualmente, a startup conta com três maneiras de comercializar sua plataforma por meio de pacotes de assinatura mensal:

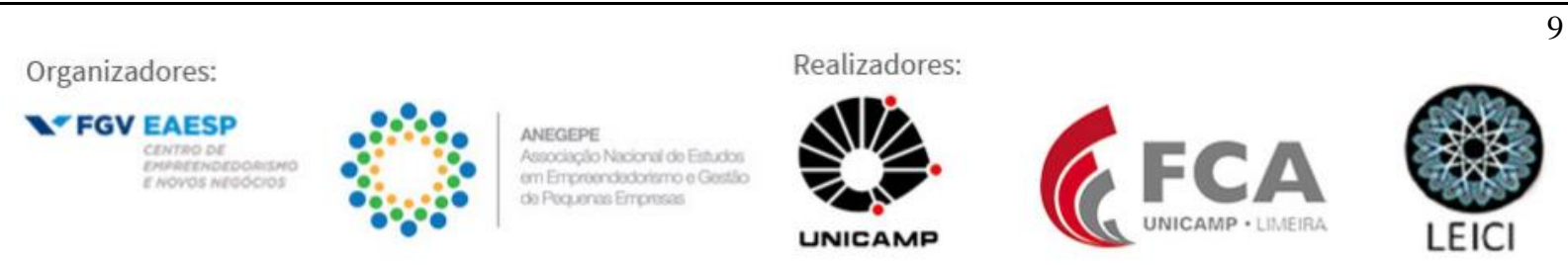


- Gratuito: podem fazer download de modelos de contratos de acordo com as suas necessidades e ajustar os contratos conforme sua necessidade de forma privada.

- Assinaturas: Permite a gestão/edição completa dos contratos na plataforma, assessoria jurídica (por meio de compra de crédito adicional), assinatura digital. Esta opção possui três modelos de precificação, de acordo com o número de usuários e volume de contratos criados na plataforma.

- Experimental por 14 dias: Todos os pacotes oferecidos de assinatura, permitem um período de 14 dias de degustação.

No ano de 2016, recebeu investimento de 50 mil reais pela aceleradora WoW para investir em ações de marketing e estruturação da plataforma para escalar sua operação.

\subsubsection{CRIATIVANDO}

A Criativando é uma startup que conecta Designers e Arquitetos em um marketplace digital para criativos, fundada por seu CEO Jonathan Tebaldi na cidade de Nova Bassano/RS em 2016. A Criativando permite que designers publiquem suas artes para criação de objetos de decoração personalizados, bem como recebam propostas de projeto de arquitetos para criação de projetos que atualmente envolvem papéis de parede, almofadas e quadros. Estes projetos são conduzidos pela plataforma e a Criativando é responsável pela aprovação, impressão e entrega dos itens de decoração, pois conta com infraestrutura gráfica para produção dos itens e o portal e-commerce.

A plataforma não requer nenhum pagamento para que os usuários cadastrem suas artes ou projetos. Todo o modelo de rentabilização da startup está baseado nas transações realizadas na plataforma, que seguem os seguintes modelos:

1. Comercialização de Almofadas, Quadros e Papéis de Parede: Os designers autores recebem $10 \%$ por cada venda realizada;

2. Projetos Personalizados para Arquitetos: Os designers autores recebem $15 \%$ do valor do projeto negociado entre a Criativando e o arquiteto.

No ano de 2017, a Criativando recebeu um aporte de 200 mil reais da aceleradora gaúcha Ventiur, que permitiu a formação de um time de desenvolvimento em tempo integral para seguir na evolução do Marketplace.

\subsection{MÉTODOS UTILIZADOS}

\subsubsection{ESTÁGIO DE CRESCIMENTO DE USUÁRIOS E CANAIS DE VENDA}

A Rocket.chat tem como pauta principal de aquisição de clientes a melhoria constante da sua plataforma. Por ser uma plataforma open-source a startup investe suas energias em se manter ativa na comunidade de desenvolvimento para que o crescimento da base de usuários e funcionalidades seja originado da sua comunidade. Segundo Gabriel Engel, CEO da Rocket.chat:

“Tornar aberto o código do produto e disponibilizá-lo de maneira gratuita,é a principal estratégia da nossa empresa. Assim removemos as maiores barreiras que empresas e organizações podem ter para experimentarem nossa ferramenta. (...) A Rocket. Chat também investe muito na sua relação com a comunidade internacional de desenvolvedores, participando de diversos congressos e exposições, seja como patrocinador ou muitas vezes como palestrantes. " 
Em menos de 2 anos, a Rocket.chat conta com mais de 130 mil servidores instalados, incluindo nuvem e servidores próprios, e 2 mil novos servidores instalados por semana. Isto representa um número de aproximadamente 10 milhões de usuários distribuídos em todas estas instalações do sistema.

A Santo Contrato tem como principal estratégia de marketing a otimização de seu site para aparecer bem ranqueado em sites de pesquisa (SEO). Dado que seu público são empresas que precisam de contratos e advogados, sua estratégia de penetração no mercado se dá a partir da necessidade da elaboração de contratos. Segundo o seu CEO Marcel Boff e o CMO Lucas Cunha, o principal canal de aquisição da Santo Contrato é o Google AdWords. Até o momento a startup conta com quase 5 mil usuários cadastrados na plataforma, uma média de 300 usuários ativos e 50 mil acessos a sua plataforma por mês.

Por fim, a Criativando está adotando como principal estratégia de aquisição de clientes a visita presencial aos escritórios de arquitetura. Apesar da plataforma ser 100\% digital, a Criativando ainda está em uma etapa inicial que requer a descoberta de quais são as principais causas de os arquitetos não confiarem a produção de papéis de parede e projetos a plataformas digitais. Segundo Jonathan Tebaldi, CEO da Criativando, o principal desafio na aquisição de clientes está na desconfiança dos arquitetos sobre o tipo de material vendido na internet. Portanto o Jonathan busca neste estágio buscar o reconhecimento de grandes escritórios de arquitetura para fortalecer seu marketing de indicação. Até dezembro de 2017, a startup contava com 30 arquitetos cadastrados na plataforma e 22 pedidos já realizados, o que totaliza um faturamento de $\mathrm{R} \$ 50.000,00$.

\subsubsection{TESTES REALIZADOS X PERFORMANCE DOS MÉTODOS UTILIZADOS}

Durante as entrevistas, foi possível perceber que todas as startups que participaram do estudo percorriam o ciclo Construir - Medir - Aprender proposto por Ries (2012) para buscar novos usuários para seus produtos. Portanto cada uma delas, lançava uma hipótese de abordagem ou campanha e media os resultados. Desta forma era possível ajustar as estratégias de aquisição e decidir qual estratégia devia ser mantida ou descontinuada. Vale ressaltar que, para Criativando e Santo Contrato, estes métodos de aquisição além de auxiliaram nos testes e validações das suas audiências, provocaram uma mudança importante na definição de público-alvo de suas soluções.

No caso da Criativando, Jonathan Tebaldi (CEO) descobriu em suas primeiras ações que a sua primeira hipótese de cliente: os Arquitetos, não realizavam compra de material de papel de parede pela internet, pois acreditavam que só era vendido adesivos de baixa qualidade. Por essa razão, resolveu pivotar sua estratégia para conectar arquitetos com projetistas, que garantissem uma exclusividade no projeto e por fim, trouxessem confiança na qualidade dos produtos que seriam gerados dessa relação. Eis que essa descoberta, fez com que surgisse o Marketplace de criativos, onde a Criativando exerce um papel de mediador, executor e entregador dos produtos criados entre os arquitetos e designers. Além disso, descobriu que a partir do crescimento da sua base de designers, poderia desenvolver um modelo de licenciamento para criação de itens de decoração. No momento a startup define seu público alvo como designers e arquitetos jovens. É importante destacar que neste caso especialmente, o empreendedor monitora poucos indicadores, o que desfavorece a análise qualitativa de cada

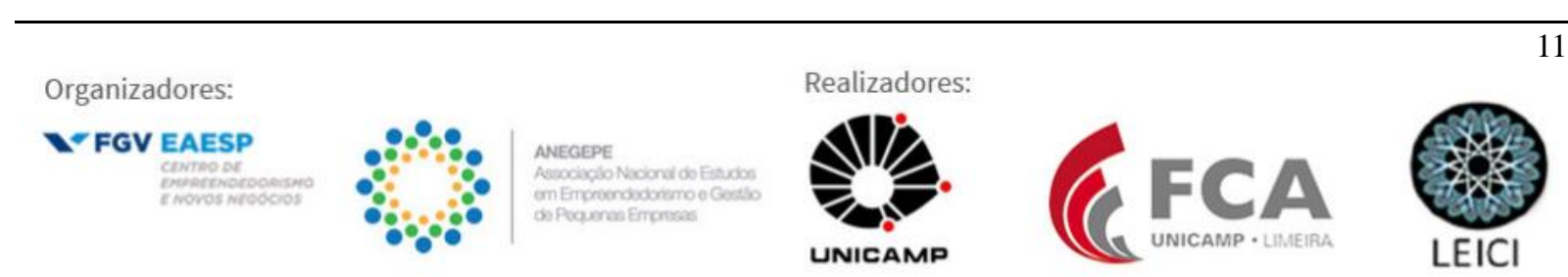


método empregado na aquisição de clientes. Isso se dá em grande parte, também pela experiência do empreendedor, que também se desenvolve ao longo da trajetória empreendedora. Entretanto, este relato evidencia a importância do feedback dos clientes para ir ajustando a estratégia da startup.

Já a Santo Contrato tinha como posicionamento inicial atingir apenas os empresários de pequeno e médio porte, garantindo contratos de qualidade sem necessariamente envolver um advogado. Após as primeiras experiências com os usuários, percebeu que as pessoas ainda assim careciam de um advogado, entretanto o principal interessado na velocidade do processo eram os empresários. Neste momento, a empresa passou a se posicionar não apenas como uma plataforma de contratos, mas de ganho de produtividade. Seus sócios buscaram escritórios de advocacia para experimentar a plataforma e ganhar seus clientes consequentemente, entretanto os sócios geralmente não enfrentavam a rotina da burocracia para elaborar contratos e consequentemente não demonstravam interesse na ferramenta. Por estes fatores, neste momento a startup define que seu público alvo são empresários que buscam acelerar a elaboração e assinatura de seus contratos.

As evidências indicam que, mesmo em startups de produtos puramente digitais, as ações no meio físico ainda possuem grande importância no momento de criar relevância em comunidades de nicho. Isso foi observada em 2 das startups analisadas, que mantem em ritmo acelerado a realização de apresentações de seus produtos em eventos especializados. Estas ações geralmente possuem baixo custo e combinadas com convites e experimentações, geram um buzz numa comunidade local importante. É importante destacar que a eficácia de cada método depende de muitas variáveis como: forma de aplicação, canais de distribuição, público alvo e investimento.

\subsubsection{GROWTH HACKING}

O Growth Hacking é uma das principais formas de aquisição de usuários até então da Rocket.chat, o fato do produto ser open source garante que seus releases realmente engajem a comunidade para seguir usando e melhorando o produto. Segundo Gabriel Engel, essa estratégia Product Centered foi o principal motivador para a startup seguir crescendo de maneira forte. É possível observar que nesta estratégia ficam claros os elementos de uso dos usuários em rede para fortalecer sua presença de mercado. Pois permite que os próprios usuários customizem o produto e sintam-se parte da construção. O Growth Hacking neste caso está na presença ativa em comunidades de nicho que possuem potencial de alavancar a presença do produto no mercado e também adquirir clientes de maneira indireta.

Já na Santo Contrato o hacking utilizado foi o mapeamento de todos os tipos de contratos mais pesquisados na internet e oferecer modelos pré-prontos para visualização de qualquer pessoa. Aproveitou-se de palavras em evidência (buzz) para originar tráfego a partir de mecanismos de buscas por termos que não necessariamente possuem vínculo com a marca da startup.

\subsubsection{BUZZMARKETING E MERCHANDISING}

$\mathrm{Na}$ Rocket.chat além das ações no meio digital, a empresa realiza também ações no meio físico. Segundo o Gabriel Engel, a startup patrocina eventos de onde os maiores defensores da

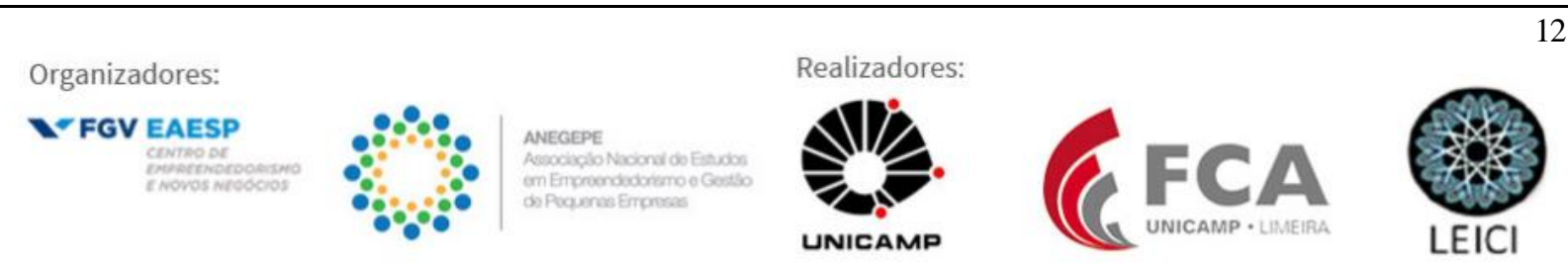


Rocket.chat, os desenvolvedores, se encontram, assim como os potenciais decisores de utilização, profissionais com cargos administrativos em grandes empresas. Exemplo de eventos que foram patrocinados em 2017: The Developers Conference, RD Summit, Latinoware, Conexão Kinghost, BrazilJS. Além disso, pode-se observar que essas ações geram relevância no grupo de nicho no qual o evento ocorre e também em veículos públicos de comunicação que acompanham o evento e geram buzz para a startup, que fortalece suas ações de topo de funil para aquisição de clientes.

Já a Criativando, aposta no buzzmarketing como uma estratégia conectada com o merchandising. Segundo Jonathan Tebaldi, a startup está fechando contratos com grandes marcas para licenciar produtos em sua plataforma. Exemplo foram itens de decoração licenciados pela Netflix para o Seriado Narcos. Recentemente aproveitou o momento de uma música famosa para lançar uma almofada em seu e-commerce com refrão e fazer publicidade cruzada com o perfil da cantora. Este tipo de ação aproveita de elementos como WOW (wordof-mouth) para conseguir compartilhamentos e vincular sua startup a marcas e artistas renomados como forma de tracionar suas ações de marketing.

No caso da Santo Contrato, a startup está ainda em fase de construção do teste da próxima hipótese para aquisição de clientes para sua startup usando de buzzmarketing. Entretanto, revelou durante as entrevistas que a estratégia será escrever sobre o mercado de Lawtechs (startups que oferecem soluções para o mercado jurídico) e mencionar todos os tipos de empresas existentes. Segundo o Lucas Cunha, essa estratégia tem como objetivo gerar compartilhamentos na audiência de seus concorrentes que possuem usuários com perfil e necessidades similares a da Santo Contrato. Ainda não possui dados para medir esta estratégia, mas é válido pois trata-se do momento inicial de construção de um case de crossmarketing. Muito utilizado para atingir públicos diretos por meio de conteúdos que falam sobre assuntos indiretos ao produto ou serviço oferecido pela startup.

\subsubsection{PITCHS E APRESENTAÇÕES}

As apresentações e pitchs realizados pelo time da Rocket.chat são uma das estratégias que sustentam as ações de engajamento de sua comunidade de desenvolvedores e atraem replicadores de sua marca. Segundo relato do Gabriel Engel, como a plataforma possui uma história admirável, que ocorre com dificuldade no mundo empresarial, "um executivo que teve sucesso com o sonho de criar um produto totalmente colaborativo e gratuito", nós utilizamos técnicas de storytelling para cultivar uma cultura de adoração pela empresa. Junto às interações digitais, mensalmente integrantes da empresa realizam palestras pelo mundo, permitindo que as pessoas vejam as pessoas por trás do projeto.

Já a Criativando por centralizar sua aquisição de clientes nos meios digitais por buzzmarketing e no off-line por meio de visita aos escritórios, pode-se observar que as apresentações realizadas pelo empreendedor estão muito ligadas ao reconhecimento da comunidade empresarial, bem como no ganho de relevância em veículos públicos de comunicação que realizam a cobertura destes eventos, do que na aquisição direta de clientes. Entretanto, este tipo de ação não é menos importante, pois estas citações e reconhecimentos por mídias cruzadas dão confiança para futuros clientes na hora de consumir o produto ou serviço de uma empresa jovem no mercado.

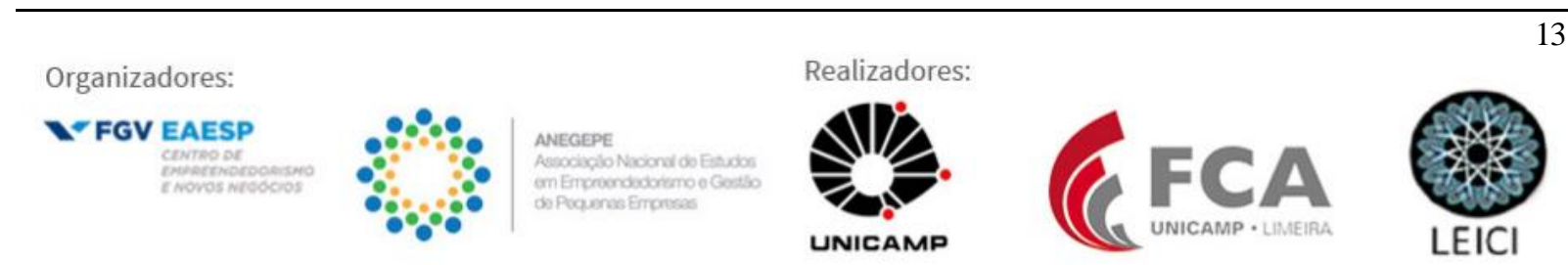




\subsubsection{PROPAGANDA ONLINE}

$\mathrm{Na}$ Rocket.chat o Gabriel relata que o investimento em publicidade online nas redes sociais da startup é responsável pela captura de leads e empresas que se enquadram no modelo SaaS que conta até o momento com 20 empresas que pagam uma assinatura mensal para ter suporte e atualizações da plataforma. Dado o momento em que a empresa formatou uma oferta SaaS para o público $\mathrm{B} 2 \mathrm{~B}$, as redes sociais permitem o refinamento da audiência para que sejam mais assertivos na divulgação do seu produto. Portanto, essa é uma abordagem que tende a seguir com um investimento importante pela startup para continuar crescendo a sua base de clientes que geram receita recorrente.

No caso da Criativando, o empreendedor Jonathan Tebaldi relata que a estratégia de investir em publicidade fracassou, a Criativando investiu aproximadamente 20 mil reais e obteve um volume baixo de clientes e pedidos. Vale ressaltar que a performance deste tipo de ação também está muito ligada ao nível de conhecimento dos clientes para que a audiência selecionada no momento das publicações esteja alinhada com o nicho correto de potenciais cliente. Caso contrário, a startup estará competindo em um oceano onde grandes empresas investem muito dinheiro e possuem muito mais fôlego financeiro.

\subsubsection{MARKETING DE INDICAÇÃO}

Descobriu-se durante as entrevistas que essa estratégia ainda é pouco explorada pelos empreendedores entrevistados. Foi citada apenas pelo Lucas Cunha da Santo Contrato, que utiliza esta abordagem ainda de forma tímida, oferecendo em seu site apenas um local para indicar amigos. Mesmo que pouco explorada, segundo o empreendedor, a estratégia foi muito simples de ser implementada e já gera um resultado expressivo. É muito importante saber qual o momento de pedir indicação a um cliente, entretanto a estratégia de manter um canal aberto para receber indicações é uma estratégia que se não aplicada, com certeza a startup deixa de adquirir clientes com alto poder de conversão. Logo, não pedir indicações é ainda pior que pedir eventualmente em um momento incorreto, pois custa muito menos que mídia paga e converte muito mais (HUGHES, 2005).

\subsubsection{VENDAS PRESENCIAIS}

Esta abordagem foi mencionada apenas pela Criativando, pois parte do seu portfólio está em venda de projetos e segundo o Jonathan Tebaldi, seu cliente ainda possui muita desconfiança sobre a qualidade dos produtos vendidos em portais online. Além do fator exclusividade ser importante para os arquitetos. O empreendedor diz saber que este modelo de aquisição foge do padrão de um modelo de negócios escalável, pois exigiria o crescimento da força de vendas, junto com o crescimento da empresa. Entretanto, acredita que esta ação é temporária, até que a marca seja reconhecida, bem como o surgimento de arquitetos jovens evolua. Dado que grande parte da desconfiança, ocorre por arquitetos mais experientes que ainda dominam o mercado da sua região de atuação.

\section{CONCLUSÃO}

Este artigo buscou explorar contexto de startups digitais e com alto potencial de crescimento e escalabilidade, porém ainda em estágio de descoberta e amadurecimento do seu modelo de negócios. Nesse contexto, o objetivo foi analisar e comparar as estratégias inovadoras

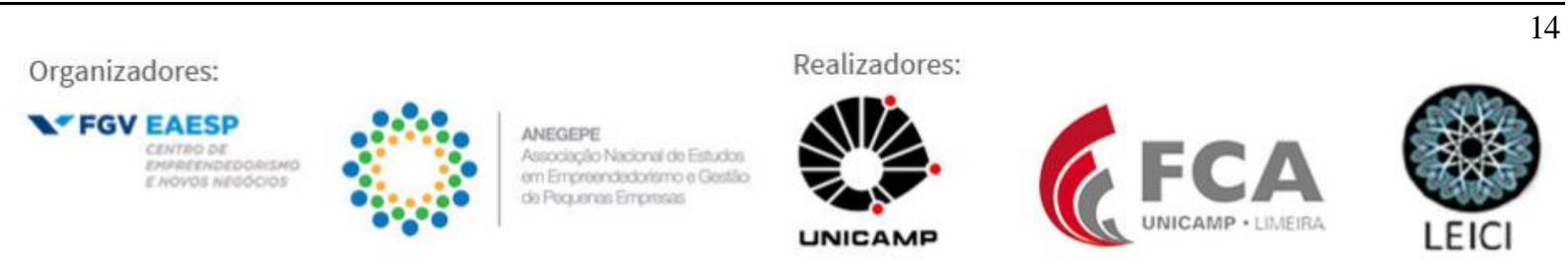


utilizadas por startups digitais para adquirir novos clientes, por meio de um estudo de múltiplos casos.

Este estudo identificou que um dos principais métodos de aquisição de usuários utilizados pelas startups analisadas foi permitir a utilização de seus produtos e serviços de maneira gratuita em comunidades de nicho. Essa estratégia foi adotada em função dos produtos e/ou serviços ofertados pelas startups ainda não possuírem características validadas pelo mercado. A principal justificativa para esta abordagem é de que a oferta gratuita elimina uma barreira inicial de uso que é o custo. Logo, a retirada do custo no momento inicial garante que a startup possa seguir executando o método de construir-medir-aprender com usuários reais.

Outra estratégia que foi adotada por todas startups analisadas é a realização de apresentações e pitchs em eventos da sua área de atuação. Segundo os entrevistados, isso é uma estratégia que não tem um custo elevado e permite conexão direta com uma audiência em potencial que pode vir a comprar o produto e/ou dar feedbacks instantâneos sobre o produto ou serviço. Esta abordagem também oportuniza que os empreendedores tenham contato com mídias públicas que podem escrever matérias sobre o evento e incluir suas startups em veículos de comunicação em massa. Algo que seria inviabilizado por propaganda direta nestes mesmos canais dado o alto custo de propaganda nestes veículos de comunicação.

Este estudo contribui com a literatura de startups ao analisar startups em estágio de incerteza e ainda em etapa de descoberta do seu modelo de negócios, à medida que a literatura analisa predominantemente startups com mais de cinco anos de operação, os desafios de uma startup nos estágios mais incipientes são negligenciados pela literatura (DELMAR; SHANE, 2004). É esse, justamente, o período crítico de uma startup. O presente estudo revela, portanto, a importância de analisar as fases iniciais de uma startup, ampliando o entendimento já existente sobre as atividades executadas por startups (DELMAR; SHANE, 2004) em um contexto de escassez para investimento em mídias tradicionais para aquisição de clientes e usuários.

Além disso, o estudo corrobora para um entendimento de como o processo de aquisição de clientes é executado em startups e, portanto, é um dos fatores chaves para a validação da aprendizagem, que segundo Ries (2012) é a métrica chave para medir progresso em uma startup. Os resultados de cada método empregado para adquirir clientes, pautava o desenvolvimento dos produtos e consequentemente ajustes em sua definição de público alvo.

Também foi possível observar que não há nenhum método totalmente novo nesta nova conjectura da economia digital, todos podem ser observados na literatura revisada neste artigo (BUTLER 2009, BLANK 2012, ISMAIL 2015, KOTLER 2017, HOLIDAY 2013 e MERCHANT 2012). Entretanto a potencialização de cada método somado aos fenômenos de comunidades digitais é o que redimensiona o potencial de cada estratégia de aquisição de clientes na era digital. Isto foi percebido por exemplo, nos casos onde a Rocket.chat patrocina eventos e disponibiliza sua plataforma para comunicação durante o evento, isso por sua vez alavanca o uso e permite que o relacionamento com a marca seja prolongado mesmo após o término da ação no meio físico.

Este estudo apresentou algumas limitações, como por exemplo, por se tratar de microempresas, a pesquisa limitou-se a visão de um entrevistado, além de outros dados secundários. Sugere-se ainda novos estudos para elucidar como o consumidor conectado em rede está modificando a abordagem de marketing na economia digital. Não apenas no
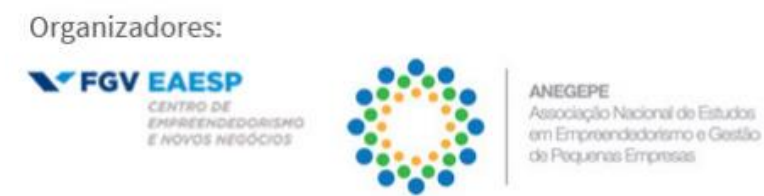
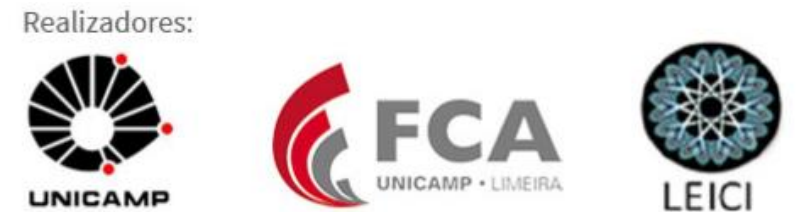
contexto de startups mas também em empresas já consolidadas, que fazem uso dos próprios clientes para promover seus produtos e serviços em seus contextos de rede.

Por fim, destaca-se que a validação recorrente de aprendizagem são o cerne do progresso de uma startup, entretanto essa validação só pode ser medida a partir da iteração com seus clientes. Logo os empreendedores possuem o desafio de selecionar as estratégias de aquisição que sejam compatíveis com a sua capacidade de investimento e obtenham maior proveito dos potenciais efeitos de rede que cada público-alvo pode gerar.

\section{REFERENCIAL TEÓRICO}

ANDERSON, Janna; RAINIE, Lee. Pew Research Center. In: The future of gamification. Washington DC, 2012. Disponível em: http://www.pewinternet.org/2012/05/18/the-future-ofgamification/ Acesso em 23 novembro 2017.

BERMAN, Barry. Referral marketing: Harnessing the power of your customers. New York; Business Horizons. 2016. Vol. 59 Issue 1, p19-28. 10p. Jan 2016.

BLANK, Steve; DORF, Bob. The Startup Owner's Manual: The Step-By-Step Guide for Building a Great Company. California: K\&S Ranch, 2012.

BLANK, Steve. The four steps to the Epiphany: Succesfull Strategies for Products that Win. California: Lulu.com, 2006.

BLANK, Steve. Harvard Business Review. In: Why the Lean Start-up Changes Everything. Massachussets, 2013. Disponível em: <https:/hbr.org/2013/05/why-the-lean-start-upchanges-everything> Acesso em: 22 maio 2017.

BLANK, Steve. Why the lean start-up changes everything. Harvard business review, 2013. v. 91,n. 5, p. 63-72.

BUTTLE, Francis. Customer Relationship Management: Concepts and Technologies. Massachussets: Elsevier, 2009.

CERQUEIRA, Renata; SILVA, Tarcizio. Marcas e engajamento digital: algumas considerações. In: GOMES, Wilson; REIS, Lucas (Org.). Publicidade Digital: Formatos e Tendências da nova fronteira publicitária. Salvador: P\&A Editora, 2011.

DAMODARAN, Aswath. Corporate Finance: First Principles, New York, 2012. Disponível em: < http $/ /$ pages.stern.nyu.edu/ adamodar/New_Home_Page/background/cfin.htm>

DULLIUS, Andreia Cristina: As Capacidades de Inovação em Startups: um estudo no vale do silício. Dissertação (Mestrado) — Universidade Federal do Rio Grande do Sul, Porto Alegre, 2016.

GIL, Antonio Carlos. Métodos e Técnicas de Pesquisa Social. Atlas. 1999.

HOLIDAY, Ryan. Growth Hacker Marketing. New York: Penguin Publishing Group. 2013.

HUGHES, Mark. Buzzmarketing: Get People to Talk About Your Stuff. New York: Penguin Publishing Group. 2005.

ISMAIL, Salim, MALONE, Michael S., VAN GEEST, Yuri. Organizações Exponenciais: por que elas são 10 vezes mais rápidas e baratas que a sua (e o que fazer a respeito). São Paulo: HSM Editora, 2015.

\section{Organizadores:}
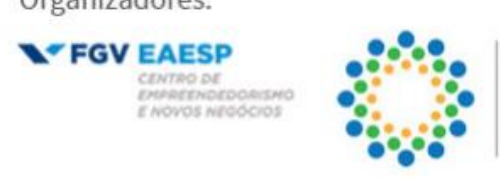

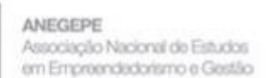

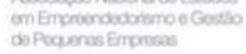

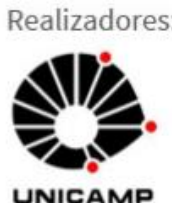


JENKINS, Henry; FORD, Sam; GREEN, Joshua. Cultura da Conexão: criando valor e significado por meio da mídia propagável. São Paulo: Aleph, 2014.

JOHNSTON, W.J., LEWIN, J.E. "Organizational buying behavior: toward an integrative framework", Journal of Business Research, 1996, Vol. 35 - pp. 1-16.

KING, Logan. Growth Hacking: The Best Kept Marketing Secrets Of Startup Hackers And Entrepreneurs. Edição do Kindle.

KOTLER, Philip; ARMSTRONG, Gary. Princípios de Marketing. Rio de Janeiro: LTC, 1999. 7.ed.

KOTLER, Philip; KARTAJAYA, Hermawan; SETIAWAN, Iwan. Marketing 4.0: Do tradicional ao digital. Rio de Janeiro: Sextante, 2017.

KUTCHER, Eric; NOTTEBOHM, Olivia; SPRAGUE, Kara. McKinsey\&Company. In: Grow fast or die slow, San Francisco, 2014. Disponível em: $<$ http://www.mckinsey.com/industries/high-tech/our-insights/grow-fast-or-die-slow $>$ Acesso em: 08 junho 2017.

LUO, Xueming; ZHANG, Jie. How Do Consumer Buzz and Traffic in Social Media Marketing Predict the Value of the Firm?. Texas: Journal of Management Information Systems. Fall. 2013, Vol. 30 Issue 2, p213-238. 26p.

LOOYESTYN, Jemma; KERNOT, Jocelyn; BOSHOFF, Kobie; RYAN, Jillian; EDNEY, Sarah; MAHER, Carol. Does gamification increase engagement with online programs? A systematic review. South Australia, 2017. PLoS ONE. 3/31/2017, Vol. 12 Issue 3, p1-19. 19p. MATTAR, Fauze Najib: Pesquisa de marketing. Atlas. 1996.

MARCONI, Marina de Andrade.; LAKATOS, Eva Maria: Técnicas de pesquisa: planejamento e execução de pesquisas, amostragens e técnicas de pesquisas, elaboração, análise e interpretação de dados. Atlas. 1996.

MARION, Tucker J; FIXSON, Sebastian K.. Harvard Business Review. In: As quatro formas de inovar na economia digital. Massachussets, 2016. Disponível em: $<$ http://hbrbr.uol.com.br/as-quatro-formas-principais-de-inovar-na-economia-digital/> Acesso em: 16 novembro 2017.

MERCHANT, Nilofer. 11 Rules for Creating Value in the Social Era. Massachusetts: Harvard Business Review Press, 2012.

OSTERWALDER, Alexander; PIGNEUR, Yves. Business Model Generation: Inovação em Modelos de Negócios: um manual para visionários, inovadores e revolucionários. Rio de Janeiro: Alta Books, 2011.

RASMUSSEN, E.; TANEV, S. Lean start-up: Making the start-up more successful. Start-Up Creation. Woodhead Publishing, 2016. p. 39-56, 2016.

RIES, Eric. A Startup Enxuta: Como Os Empreendedores Atuais Utilizam a Inovação Continua para Criar Empresas Extremamente Bem-sucedidas. São Paulo: Leya Brasil. 2012.

ROESCH, Sylvia Maria Azevedo. Projetos de Estágio e de Pesquisa em Administração: guia para estágios, trabalhos de conclusão, dissertações e estudos de casos. Atlas. 1999

SREEJESH, S.; MOHAPATRA, Sanjey.; ANUSREE, MR. Business research methods. [S.1.]: Springer, 2014.

THIEL, Peter; MASTERS, Blake. Zero to One: Notes to startups, or how to build the future. New York: Crown Business, 2014.

YIN, Robert K. Case study research: Design and methods. [S.1.]: Sage publications, 2013. 